\title{
Librarians as advocates of social media for researchers: A social media project initiated by Linköping University Library, Sweden
}

\author{
Sassa Persson and Maria Svenningsson
}

\section{Linköping University Post Print}

\section{Tweet}

N.B.: When citing this work, cite the original article.

This is an electronic version of an article published in:

Sassa Persson and Maria Svenningsson, Librarians as advocates of social media for researchers: A social media project initiated by Linköping University Library, Sweden, 2016, New Review of Academic Librarianship.

New Review of Academic Librarianship is available online at informaworldTM:

http://dx.doi.org/10.1080/13614533.2016.1184693

Copyright: Taylor \& Francis (Routledge): Library and Information Science http://www.routledge.com/

Postprint available at: Linköping University Electronic Press

http://urn.kb.se/resolve?urn=urn:nbn:se:liu:diva-127707 


\title{
Librarians as advocates of social media for researchers: A social media project initiated by Linköping University Library, Sweden
}

\begin{abstract}
Librarians at Linköping University help researchers keep abreast of developments in their fields and to increase the visibility of their work. Strategic, professional use of social media ought to be an essential part of a researcher's communication strategy. This article investigates the level of awareness of the professional use of social media amongst LiU researchers. The investigation showed that use of social media was not significant, however a small number saw potential. The purpose of this article is threefold: first to evaluate the potential of using social media as a tool for communicating research outside LiU. Secondly, the article presents a study in which views of LiU researchers on social media were ascertained via seminar discussions, informal feedback and interviews. The study has a case study approach involving eight researchers. Thirdly, the article covers how LiU Library created a web-based information package to support researchers in social media use.
\end{abstract}

Keywords: Social media research support, Scholarly social media, Social media tools, Social media strategy, Academic libraries, Research support. 


\section{INTRODUCTION}

Linköping University Library (LiU Library) has used various forms of social media (Facebook, Twitter and Instagram) to interact with users over the last four years and as such has an expertise in social media tools: how they are used, their benefits and limitations. Furthermore, the Library's role in analyzing the publication output from the University via bibliometric analysis and subsequent involvement with researchers' publishing strategy, made us aware of the potential of social media as a communication tool for researchers. We saw an opportunity for Linköping University (LiU) to increase the visibility of its research, using social media as a communication tool. The aim of this article is to evaluate the potential of using social media as a tool for communicating research outside LiU. This article also presents a study of a project in which views of LiU researchers on social media were ascertained via seminar discussions, informal feedback and interviews.

In 2014, LiU Library initiated a project in collaboration with the Communications and Marketing Division and the ICT studio (Information and Communication Technologies) at LiU, to develop a multiple approach to interact with researchers to identify the social media usage of LiU researchers. These departments also work with social media at LiU and as such were natural collaboration partners in the project and the creation of a web-based information package to support researchers in their social media use. During the autumn of 2014 , we briefly examined the web sites of six major Swedish university libraries' looking for web-based support on social media for researchers that could serve as an inspiration for our project. We could not find any examples of prominently placed services on any library web site. Outside Sweden, we were inspired by two guides; one created by Newcastle University Library, "Social media for research" 
(http://libguides.ncl.ac.uk/socialmedia) and a guide by Mollett, Moran \& Dunleavy

(2011), "Using Twitter in university research, teaching and impact activities"

(http://eprints.Ise.ac.uk/38489/).

As part of the library's work with LiU's bibliometrics analyses, members of the project group (staff from the department of Publishing Infrastructure and the Communications and Marketing Division), participated in some 45 seminars during 2014 and 2015 presenting the analyses and equally addressing publishing strategy. As part of publishing strategy, ideas and techniques for making use of social media were presented. Each of these seminars was followed by a discussion session in which researchers' views on the role of social media in a professional context was brought up, to ascertain their awareness and knowledge level. During the same period four open seminars were hosted by the authors of this article and two colleagues from the department of Publishing Infrastructure on research communication with a focus on new ways of publishing and distributing research using social media.

\section{Researchers and social media}

Keeping up to date poses a constant challenge for researchers. A part of this revolves around how communication channels in the research world (e.g. conferences, personal contact, e-mail etc.) are being complemented with social media tools such as Linkedln, Twitter, blogs and scholarly social media platforms including ResearchGate and Academia.edu, to network, voice opinions and share journal articles. With the addition of these new communication channels comes the importance of building a brand and establishing a social media presence to stay 
visible, in order to attract potential collaborators and funders (Bik \& Goldstein, 2013; Tregoning, 2016).

International studies show that some researchers are active users of social media tools and that the numbers are increasing, but the majority still remain hesitant (Lupton, 2014; Mas-Bleda, Thelwall, Kousha \& Aguillo, 2014). A researcher should consider social media as a communication tool since it is becoming more common that universities and funding agencies, especially in the US and the UK, are convinced that outreach activities are important both for promoting and explaining research to the public (Scott, 2013; Wilkinson \& Weitkamp, 2013). Further, Bik and Goldstein (2014) adds "A growing body of evidence suggests that public visibility and constructive conversation on social media networks can be beneficial for scientists, impacting research in a number of key ways" (p. 1). Academic success is frequently measured in terms of impact and where there is evidence that increased distribution of one's publications leads to increased impact, researchers are more likely to use social media as a communication tool.

\section{BACKGROUND/CONTEXT}

In Sweden there are 48 universities and university colleges. Most universities in Sweden are publicly funded, Linköping University being one of them.

$\mathrm{LiU}$ is located in the south of Sweden. It is a multi-campus university with four campuses, located in three different cities. The university has approximately 27000 students, 4000 employees of which 300 are professors and $1300 \mathrm{PhD}$ students. It is one of Sweden's larger universities. LiU, which recently celebrated 40 years as a university, has four faculties; Arts and Sciences, Medicine and Health Sciences, Educational Sciences and Science and Engineering. LiU has strong internationally 
recognized research environments in materials science, information technology and disability studies. LiU has four libraries, located on the different campuses, and has 100 employees, 70 of these are librarians. Linköping University Press, an open access publisher, is part of the library as well as the department of Publishing Infrastructure. Subject librarians and the department of Publishing Infrastructure provide research support at LiU.

\section{LITERATURE REVIEW}

Studies show (e.g. Bik \& Goldstein, 2013; Liang et al., 2014; Lupton, 2014; Van Noorden, 2014) that social media offers great potential for researchers to help them keep up to date with new developments in their field and to distribute their research output. Reaching wider audiences helps researchers increase their visibility and ultimately the impact of their research. Liang et al. (2014) state that "Being cited or mentioned on Twitter could be a new sign of one's academic impact" (p. 776).

\section{Social media strategy}

Having a social media strategy is helpful in achieving the aim of increasing visibility and impact. A well-formulated strategy helps to establish contact with the "right" people while networking and identifying the most appropriate social media tools to distribute one's research. It should identify target groups and establish objectives to identify the most effective channels to use, depending on purpose or agenda (Bik \& Goldstein, 2013). A researcher needs to know who their audience is. If the desired target group is not using the same communication channels the strategy will fail and will need to be modified (Woolman, 2014). Further, by identifying risks or potential pitfalls, unnecessary stress can be avoided (Lupton, 2014). 
A social media strategy will also help manage a researcher's social media return on investment (ROI) (Schaffer, 2013); researchers invest their time in social media, making it crucial that their time is well spent (Woolman, 2014). Besides defined objectives, also mentioned by Bik and Goldstein (2013), Schaffer (2013) writes that tactics and metrics are essential in a well-formed social media strategy in order to manage and make sense of social media activities. Frequently reviewing and optimizing a social media strategy is a necessity since social media tools keeps changing, as well as methods of use.

\section{Setting up a social media strategy}

Schaffer (2013) refers to the PDCA cycle, as a suitable tool for setting up a social media strategy with an action plan. PDCA stands for:

- Plan, referring to social media strategy

- Do, referring to implementation of the strategy

- Check, referring to analyzing

- Act, referring to adjust strategy

After a social media strategy has been created with defined objectives, target groups and choice of tools to use, implementation of the strategy takes place. One needs to set up measurable goals which have to be analyzed. If the desired outcome is not achieved the strategy needs to be adjusted. The cycle is infinite and has to be repeated many times during the process. While Schaffer's (2013) book is written for the marketing and business sector much of it applies to the research community and for research communication. 


\section{Social media tools and scholarly social media platforms}

"Social media" covers a wide range of resources and choosing which to use is not self-evident. It is better to use fewer social media tools than too many but there are no "rules" about which ones to use (Schaffer, 2013). Research has however been carried out on which tools are most preferred by researchers. 3500 researchers from 95 countries participated in a survey conducted by Van Noorden (2014). The result from the survey concluded that researchers preferred Twitter as a professional communication channel rather than Facebook which many found was more suitable for personal use. Twitter was primarily used to follow discussions, to comment on research and post work-related content. The survey also showed that it was common for researchers to create professional profiles with scholarly social media platforms such as ResearchGate and Academia.edu for networking with peers and to discover articles in their fields. Researchers also showed an interest in tracking metrics such as views and downloads from their account (Van Noorden, 2014).

Another survey showed similar results. 711 academics from the UK, Australia/New Zealand, the US, continental Europe and Canada were surveyed and Lupton (2014) found that those who used social media in a strategic way saw benefits such as the opportunity to start professional networks and to promote and share their own work. Speed of communication via social media platforms was noted by respondents as a major advantage. Difficulties with the boundaries between their private and professional lives when using social media in a professional setting were also reported. Concerns were raised that they might undermine their professional reputation if being too personal. The surveys indicated that the most common tools 
used by researchers is a combination of Twitter and ResearchGate and/or Academia.edu.

Researchers' choice of Twitter as a communication tool is also supported by other's findings. Yeo et al. (2014) surveyed tenure-track scientists at the University of Wisconsin-Madison and found that "Scientists who perceived social media as effective communication tools were more likely to use Twitter" (p. 1). Further, Yeo et al. (2014) made a comparison between Twitter and Facebook, and found that researchers prefer Twitter. This, speculates Yeo et al. (2014), is because researchers find Twitter to be a more professional application, thus agreeing with Van Noorden's (2014) findings. Yeo et al. (2014) adds that ResearchGate and Academia.edu are tailored online communities for researchers, making Facebook superfluous.

\section{Early-career vs senior-career researchers}

Findings from a small study (Nicholas et al., 2015) suggest that early-career scholars have more to gain by using emerging platforms (eg. ResearchGate/Academia.edu). The reason for that could be that early-career researchers are not yet as established as senior researchers due to fewer active years in the profession. Another explanation for this could be because early-career academics to a large extent are the ones that are pushing the transition to (Cyber-) Science $2.0^{1}$ forward and thus know how to handle Web 2.0 better than their later career colleagues (Nentwich \& König, 2014).

\footnotetext{
${ }^{1}$ Cyberscience 2.0 is a related term to Science 2.0 referring to scientists using web 2.0 tools such as social networks (Nentwich \& König, 2012)
} 


\section{METHODOLGY}

The study has a case study approach. Yin (2004) refers to a case study as a small qualitative study where multiple methods often are used "...to produce a first-hand understanding of people and events" (р. 3). We carried out approximately one-hourlong, informal, one-to-one interviews with eight researchers at LiU who use social media professionally. The eight were between 30 and 60 years old, two of them were women. One of them is doing a PhD, three were early-career researchers, having obtained their PhDs within the past eight years. The other four were seniorcareer researchers and had finished their PhDs more than ten years ago. They were active in disciplines such as computer and information sciences, life sciences, social sciences and humanities. All of the researchers had teaching duties at their faculties.

The interviews were held during the autumn of 2015 and were conducted by the authors of this article. Researchers were selected by the preferences of subject discipline, age and gender, although it should be noted that at the point when candidates were being looked for, there were relatively few researchers actively using social media for research. Ten researchers who use social media were contacted by e-mail and eight responded, agreeing to be interviewed. The other two declined due to other engagements. The following open questions formed the base of the interviews:

- Which social media tool or scholarly social media platform do you use?

- How did you select which tool or platform to use and which not to use?

- How long have you been using social media?

- How much time do you spend using social media per week?

- For what purpose do you use social media?

- Which target groups are you targeting? 
- Have you used a social media strategy when setting up a tool or platform?

- Do you receive any response on your research from visitors to your social media tool or scholarly platform?

- Compared to your colleagues, to what extent is your commitment to social media?

- Do you receive enough support from the University on using social media?

\section{RESULTS}

Our project to identify social media usage by researchers at LiU identified the following key themes: LiU researchers' opinions on social media as retrieved from seminar discussions, Reported benefits with social media amongst interviewed LiU researchers, Choice of social media communication channels, Social media and impact, Limitations identified in interviewed LiU researchers' social media strategy and Support in using social media. These findings will now be explored.

\section{LiU researchers' opinions on social media as retrieved from seminar discussions}

In essence, the majority of the researchers we talked to at the seminars we hosted had not thought about using and hence did not really understand how to use social media effectively in a professional setting but were curious enough to take part in the discussions. Social media was seen as:

- Time consuming

- Too difficult to learn

- Having irrelevant audiences

- Being for private rather than professional life

- Having too short a message length (referring to Twitter) 
Concerns were also raised as to whether social media activity really increases the impact of a research publication. One researcher saw social media in a professional setting as highly unreliable and preferred traditional communication channels.

\section{Reported benefits with social media amongst interviewed LiU researchers}

The eight researchers that we conducted informal interviews with were positive towards social media, and had already adapted social media tools and found that it was worth the effort. The researchers had being used social media in a professional capacity for between 6 months and 6 years. The estimated time of usage per week was between 30 and 60 minutes. All estimated that they were more active on social media compared to their colleagues.

A senior-career researcher argued that it is important to serve as a good example for students and junior researchers and to be where they are. Having started using social media a year previously he believed it was necessary to be responsive and open to changes in the academic world. He also stated that social media presents excellent opportunities to get in touch with researchers internationally. Another senior-career researcher noticed that early-career researchers often use social media to a greater extent than senior-career researchers. The PhD student reported noticing that other PhD students often use social media as a way to gather information and to build a professional network which was similar to others findings (Lupton, 2014, Nicholas et al. 2015).

\section{Choice of social media communication channels}

We observed that the interviewed LiU researchers often used Twitter or scholarly social media platforms like ResearchGate or a combination of both, similar to others' 
findings (Lupton, 2014; Van Noorden, 2014). The most common purpose they gave for using social media was to monitor their field by following other researchers and to find interesting articles. Three responded that they took part in discussions and in an active way worked on boosting their online presence and their research. They reported sometimes receiving responses from other researchers after posting content.

\section{Social media and impact}

Two of the researchers we interviewed were interested in how social media activity around a publication can be used as a measure of its impact. They described traditional bibliometrics (e.g. counting citations to a publication) as slow and saw potential with using measures of social media activity discussing a publication because of its relative speediness. One, however, mentioned that discussions in social media can be a bit shallow and often involve much broader audiences than only academics, raising questions as to whether measuring the impact via social media was equivalent (and meaningful) to measuring via more traditional techniques. Another researcher went so far as to suggest that the Swedish system for research funding might start to look at researcher's impact in social media.

\section{Limitations identified in interviewed LiU researchers' social media strategy}

Objectives, target group and professional identity

Most of the researchers we interviewed had to some extent defined an objective and thought about which social media platform to use and which target group they wanted to address. Some were more interested in reaching the general public, some the scientific community and some both. There were however some important elements missing in their social media strategy. Five reported having problems 
finding their professional identity, using social media professionally versus privately on their chosen platforms. They tried to keep their private and professional lives separate by having different accounts for private and professional use. One started to use Twitter for personal use and then expanded to using it professionally. Another dimension added to this was difficulties with identity when representing themselves versus their research group. They noticed that other researchers seemed to struggle with their professional identity too, i.e. the same concerns respondents reported in the survey by Lupton (2014). We found that a common way to promote a specific research group or a journal was to create an account for that specific reason.

Engage audience, plan content and identify risks

Few seemed to have a strategy on how to get to know and engage their audience, how to plan content accordingly and how to identify risks. Our findings show similarities with a study by Wilkinson and Weitkamp (2013), reporting “...the notion that researchers remain relatively non-strategic in their dissemination strategies." (p. 6) However, all researchers reported that an increasing awareness that they needed to be more strategic in order to obtain the best result. One of them said that only in the past few years had he begun to fully realize the potential impact of social media.

\section{Support in using social media}

Despite having elements missing in their social media strategy the eight researchers saw themselves as having enough knowledge regarding social media and felt that they were not in any immediate need of support on how to use it professionally. Two researchers had however been in contact with the Communications and Marketing Division seeking guidance in setting up accounts. One researcher believed that for colleagues who are unfamiliar with social media tools, support could be 
highly beneficial. The same researcher was of the view that LiU does not see social media as a serious and professional communication channel.

\section{DISCUSSION AND CONCLUSION}

Researchers are often short of time and communicating their research is often given little priority (Wilkinson \& Weitkamp, 2013). Learning new forms of communication such as Twitter takes a certain amount of time, engagement and strategy. Thus many LiU researchers were unwilling to start using social media in their profession. The researchers we interviewed prioritized social media, and saw several benefits although some concerns were raised regarding their professional identity in social media. It is not hard to grasp why researchers struggle with their professional identity, when they are their own brand name and at the same time need to be aware that they are representing an institution. Issues with identity for the researchers we talked to were probably due to not establishing which tone of voice they should use and how they should express themselves when wanting to be professional and yet at the same time showing a bit of personality.

There is a growing trend amongst funding agencies in the US and in the UK towards looking at outreach activities. One of the researchers we interviewed speculated that the Swedish system for research funding might start to look at researcher's impact in social media. If methods that measure universities' interaction and involvement in society as a whole are developed it will be important for researchers to make use of communication channels beyond the traditional journals and academic book publishers. 


\section{Libraries and research support}

As social media tools and scholarly social media platforms like ResearchGate are becoming more frequently used by researchers, they need guidance on creating an action plan such as the PCDA cycle, a social media strategy (i.e. learning how to define objectives and target groups, planning content accordingly and identifying risks) and best practice on distributing research through these channels.

"Communication training and resources for researchers could better support them to plan, devise and support communication approaches in creative ways." (Wilkinson \& Weitkamp, 2013, p. 6). Academic libraries can play an important part in this, as many already provide researchers with bibliometrics and advice on publishing strategies. Since many researchers remain skeptical towards social media, libraries need to help researchers to think of social media as a useful tool that can lead to increased visibility and impact and not just something that is time-consuming. Ward et al. (2015) state that librarians could help or guide researchers to create profiles on scholarly social media platforms like ResearchGate or Acamedia.edu and offer support on copyright issues, journal policies etc. when uploading material to these platforms.

\section{Social media and networks for researchers (a LiU web resource)}

In the light of given facts, that researchers either need guidance or need to be encouraged to use social media, we began to think about how LiU Library could offer support to LiU researchers. We decided to create a web-based information package together with the Communications and Marketing Division and the ICT studio which we call Social media and networks for researchers, http://www.bibl.liu.se/publiceraoch-sprida/sociala-medier?l=en\&sc=true. Since many researchers struggle with time 
pressure, we wanted to make the threshold low by providing step-by-step guides to get started with social media.

The web-based information package contain sections on how researchers can use social media to best distribute publications and gain visibility, and how they can use social media to network and monitor their field. It contains specific chapters on Twitter, LinkedIn, Wikipedia, blogs, ResearchGate and Academia.edu. There is a section with model examples of researchers in Sweden and internationally that use social media for research communication, linking to their various social media profiles. The web resource is simply to inform, support and inspire those LiU researchers that are curious about social media as a tool for research communication.

Based on our findings, we recommend that academic librarians who want to support researchers in using social media 1) Find relevant collaboration partners at the university, 2) evaluate the awareness and knowledge about social media among faculty and 3) set up a communication strategy for the project. Given the limitation of the study further work will be needed. A future project could be to investigate potential difference in usage between genders and differences between early-career and senior-career researchers. It is our belief that especially early- career researchers, could benefit from use of strategic, professional use of social media to network and to disseminate their research output. 


\section{REFERENCES}

Bik, H., \& Goldstein, M. (2013). An introduction to social media for scientists. PLoS Biology, 11(4), e1001535. doi:10.1371/journal.pbio.1001535. Retrieved from: http://www.plosbiology.org/article/info\%3Adoi\%2F10.1371\%2Fiournal.pbio.100153 $\underline{5}$.

Liang, X., Yi-Fan Su, L., K. Yeo, S., A. Scheufele, D., Brossard, D., Xenos, M.,... A. Corley, E. (2014). Building buzz: (Scientists) Communicating science in new media environments: Journalism \& Mass Communication Quarterly, 1-20. doi: $10.1177 / 1077699014550092$.

Lupton, D. (2014). 'Feeling better connected': Academics' use of social media. Canberra: News \& Media Research Centre, University of Canberra. Retrieved from: http://www.canberra.edu.au/about-uc/faculties/arts-design/attachments2/pdf/nand-mrc/Feeling-Better-Connected-report-final.pdf

Mas-Bleda, A., Thelwall, M., Kousha, K., \& Aguillo, I (2014). Do highly cited researchers successfully use the social web? Scientometrics, 101, 337-356. doi: 10.1007/s11192-014-1345-0.

Mollett, A., Moran D., \& Dunleavy, P. (2011). Using Twitter in university research, teaching and impact activities. Impact of social sciences: maximizing the impact of academic research, LSE Public Policy Group, London School of Economics and Political Science., London, UK. Retrieved from:

http://eprints.Ise.ac.uk/38489/ 
Nentwich, M., \& König R, (2012). Cyberscience 2.0: research in the age of digital social networks. Frankfurt am Main [u.a.]: Campus.

Nentwich, M., \& König, R, (2014). Academia goes Facebook? The potential of social networks sites in the scholarly realm. Opening Science, 107-124. doi:10.1007/978-3319-00026-8_7.

Newcastle University Library Libguide, "Social media for research: Guide explaining how different social media tools can help at all stages in the academic research process". Retrieved from: http://libguides.ncl.ac.uk/socialmedia

Nicholas, D., Herman, E., Jamali, H., Rodríguez-Bravo, B., Boukacem-Zeghmouri, C., Dobrowolski, T., \& Pouchot, S. (2015). New ways of building, showcasing, and measuring scholarly reputation. Learned publishing, 28(3), 169-183. doi:10.1087/20150303

Schaffer, N. (2013). Maximize your social: A one-stop Guide to Building a Social Media Strategy for Marketing and Business Success. Hoboken, N.J: John Wiley \& Sons.

Scott, S. (2013). The researcher of the future... makes the most of social media. The Lancet, 381(1), 5-6. doi: http://dx.doi.org/10.1016/S0140-6736(13)60447-X.

Tregoning, J. (2016). Build your academic brand, because being brilliant doesn't cut it anymore. Retrieved from: 
https://www.timeshighereducation.com/blog/build-your-academic-brand-becausebeing-brilliant-doesnt-cut-it-any-more

Van Noorden, R. (2014). Online collaboration: Scientists and the social network. Nature, 512(7513), 126-9. doi: 10.1038/512126a. Retrieved from:

http://www.nature.com/news/online-collaboration-scientists-and-the-socialnetwork-1.15711

Ward, J., Bejarano, W., \& Dudás, A. (2015). Scholarly social media profiles and libraries: A review. Liber Quarterly; 24(4), 174-204. Retrieved from: http://liber.library.uu.nl/index.php/lq/article/view/9958/10504

Wilkinson, C., \& Weitkamp, E. (2013). A case study in serendipity: Environmental researchers use of traditional and social media dissemination. Plos one; 8(12), 1-9. Retrieved from:

http://journals.plos.org/plosone/article?id=10.1371/journal.pone.0084339

Woolman, J. (2014) Social media outcomes in academia: engage with your audience and they will engage with you. Retrieved from:

http://blogs.Ise.ac.uk/impactofsocialsciences/2014/09/24/social-media-outcomesacademia/

Yeo, S K., Cacciatore, M A., Brossard, D., Scheufele, D A., \& Xenos, M A. (2014). Science gone social. The Scientist. Retrieved from: http://www.thescientist.com/?articles.view/articleNo/40992/title/Science-Gone-Social/ 
Yin, R K. (2004). Case study methods. Revised draft, 10/1/04 Retrieved from:

$\underline{\text { http://www.cosmoscorp.com/Docs/AERAdraft.pdf }}$ 